Abstracta Iranica

Revue bibliographique pour le domaine irano-aryen

Volume 40-41 | 2019

Comptes rendus des publications de 2017-2018

\title{
Kevin T. Van Bladel. From Sasanian Mandaeans to Șäbians of the Marshes
}

Christelle Jullien

\section{(2) OpenEdition \\ 12 Journals}

Édition électronique

URL : http://journals.openedition.org/abstractairanica/50887

DOI : 10.4000 /abstractairanica.50887

ISBN : 1961-960X

ISSN : $1961-960 X$

\section{Éditeur :}

CNRS (UMR 7528 Mondes iraniens et indiens), Éditions de l'IFRI

\section{Référence électronique}

Christelle Jullien, « Kevin T. Van Bladel. From Sasanian Mandaeans to Șābians of the Marshes »,

Abstracta Iranica [En ligne], Volume 40-41 | 2019, document 2, mis en ligne le 30 décembre 2019, consulté le 27 avril 2021. URL : http://journals.openedition.org/abstractairanica/50887 ; DOI : https:// doi.org/10.4000/abstractairanica.50887

Ce document a été généré automatiquement le 27 avril 2021.

Tous droits réservés 


\title{
Kevin T. Van Bladel. From Sasanian Mandaeans to Sābians of the Marshes
}

\author{
Christelle Jullien
}

\section{RÉFÉRENCE}

Kevin T. Van Bladel. From Sasanian Mandaeans to Șābians of the Marshes. (Leiden Studies in Islam and Society), Leiden: Brill, 2017, IX p.-153 p. ISBN 9789004339460.

1 L'A. prend le parti d'étudier les origines du mandéisme non seulement à partir d'une analyse interne des textes mandéens, mais en tenant compte aussi des sources syriaques et arabes. Plusieurs chapitres sont dévolus à l'hérésiographie des mandéens, et notamment aux rapports établis entre eux et les kantéens, mais aussi les dosthéens qu'il considère comme une désignation homonyme du groupe. On notera en particulier le chap. 2 qui présente une analyse du récit de Bar Koni (env. 792) sur les origines mandéennes, et le chap. 3 qui recense trois références tirées de la littérature syriaque $\mathrm{du} \mathrm{VI}^{\mathrm{e}}$ s. sur le nom des mandéens à travers les œuvres de Nathaniel de Šahrzur, Cyr d'Édesse et les Actes de Siméon Bar Șabba'ē dont l'A. situe la rédaction dans le dernier quart du $\mathrm{VI}^{\mathrm{e}}$ s. Les chapitres 5 et 7 s'arrêtent sur l'identification des șābiens des marais méséniens avec les mandéens à partir d'un passage du Kitāb al-Dalā'il de Bar Bahlul (env. 900). C'est dans le contexte d'apaisement de la révolte des Zang dans ces zones marécageuses au IX ${ }^{\mathrm{e}}$ siècle que se situe une redéfinition du statut des mandéens par les musulmans : associés aux șābiens, ils devaient bénéficier désormais d'un statut légal qui ne fut pas sans incidence pour la survivance notamment économique du groupe. L'A. passe ensuite en revue l'ensemble des rares sources disponibles sur les siècles postérieurs (chap. 8). Il situe l'éclosion de ce mouvement baptiste en Babylonie sassanide autour du $\mathrm{V}^{\mathrm{e}}$ siècle en revisitant certaines interprétations de dates relatives notamment à la conquête arabe (voir spécialement les chap. 9 et 10) ; son hypothèse est que le mouvement aurait vu le jour au sein de groupes judéo-chrétiens qu'il donne comme "nazaréens" - parmi eux, mentionnons les elchasaïtes attestés dans l'empire partho-sassanide depuis la fin $\mathrm{du} \mathrm{II}^{\mathrm{e}}$ siècle. Le $11^{\mathrm{e}}$ chapitre est consacré à 
l'environnement religieux de l'espace babylonien à l'époque sassanide tardive. Deux appendices viennent clore l'ouvrage, l'un sur Théodore Bar Koni et l'autre sur les dialectes araméens à partir d'une lecture d'Ibn Wah̆šīya. Une bibliographie très complète est suivie d'indices utiles. Cet ouvrage fera date dans le domaine des études sur les minorités en Iran et sur le mandéisme en particulier.

\section{AUTEURS}

\section{CHRISTELLE JULLIEN}

CNRS, Mondes iranien et indien, Paris 